\title{
Length at first maturity of two species of lantern sharks (Etmopterus spinax and Etmopterus pusillus) off southern Portugal
}

\author{
Rui Coelho* ${ }^{\dagger}$ and Karim Erzini* \\ *Universidade do Algarve, CGMAR/FCMA, Campus de Gambelas, 8000 Faro, Portugal. \\ Internet: www.ualg.pt/fcma/cfrg. ${ }^{\dagger}$ Corresponding author, e-mail: rpcoelho@ualg.pt
}

\begin{abstract}
Etmopterus spinax and Etmopterus pusillus are captured in large quantities in some deep-water fisheries along the Portuguese coast and are always discarded. Specimens were collected from February 2003 to May 2004 from deep-water fisheries and classified as mature or immature. Maturity ogives were fitted and size at first maturity estimated for each sex of each species. Both species are late maturing, with the maturity sizes varying between $75 \%$ and $87 \%$ of the maximum observed sizes, depending on species and sex. For both species, females tended to mature at and grow to larger sizes than males. The late maturation of these deep-water shark species makes these populations extremely vulnerable to increasing fishing mortality.
\end{abstract}

\section{INTRODUCTION}

Elasmobranch fish have life cycles characterized by low growth rates, low fecundity and maturation attained late in their life cycle (Cortés, 2000). These general characteristics make them extremely susceptible to overexploitation (Smith et al., 1998), and once populations start to decline, it usually takes several decades before recovery can take place (Stevens et al., 2000).

Two species of lantern sharks occur off the coast of southern Portugal: Etmopterus spinax (Linnaeus, 1758) and Etmopterus pusillus (Lowe, 1839). Both these species are common by-catch and discarded by deep-water trawlers (Monteiro et al., 2001) and deep-water longliners (Erzini et al., 2001).

Previous worldwide studies that included these species have focused mainly on distributional patterns (Hareide \& Garnes, 2001; Colloca et al., 2003; Massutí \& Moranta, 2003) and general fisheries aspects (Carbonell et al., 2003). In Portugal, Coelho et al. (2003) presented a strategy to reduce by-catch of specimens captured with longlines and Santos \& Borges (2001) studied aspects of trophic relationships. The only population dynamics study known to date is the work by Sion et al. (2002) that focused on the age and growth of a Mediterranean population of E. spinax.

Given the lack of information on the fisheries biology of both these species of lantern sharks and on the impacts of fishing, it was decided to determine size at first maturity, for both males and females of E. spinax and E. pusillus, taking advantage of the regular commercial by-catches.

\section{MATERIALS AND METHODS}

Specimens were captured off the Algarve (southern Portugal) from February 2003 to May 2004, both by commercial and scientific research fishing vessels.
Commercial captures came from deep-water bottom trawls that target crustaceans such as Norway lobster, Nephrops norvegicus (Linnaeus, 1758), deep water rose shrimp, Parapenaeus longirostris (Lucas, 1846), and blue and red shrimp, Aristeus antennatus (Risso, 1816), and from
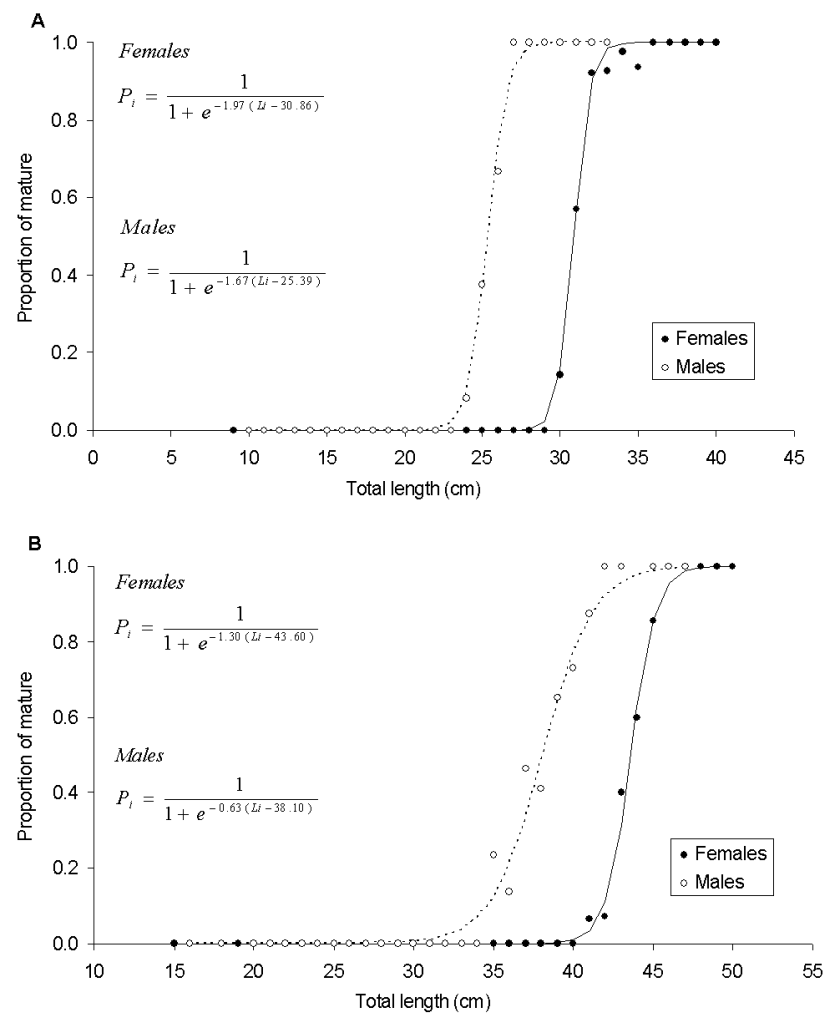

Figure 1. Maturity ogives, with the respective equations, for females and males of (A) Etmopterus spinax and (B) Etmopterus pusillus. 
Table 1. Observed size-ranges and estimated length at 50\% maturity ( $\left.L_{50}\right)$ with confidence intervals (95\% CI) for males and females of Etmopterus spinax and Etmopterus pusillus. All measurements are in $\mathrm{cm}$.

\begin{tabular}{|c|c|c|c|c|c|c|c|c|c|}
\hline \multirow[b]{2}{*}{ Species } & \multirow[b]{2}{*}{ Sex } & \multicolumn{4}{|c|}{ Size-range } & \multirow[b]{2}{*}{$\mathrm{L}_{50}$} & \multicolumn{2}{|c|}{$95 \%$ CI } & \multirow{2}{*}{$\begin{array}{c}\mathrm{L}_{50} / \text { Maximum } \\
\text { observed size }(\%)\end{array}$} \\
\hline & & Immature & $\mathrm{N}$ & Mature & $\mathrm{N}$ & & Lower & Upper & \\
\hline \multirow[t]{2}{*}{ E. spinax } & $\mathrm{F}$ & $9.1-35.7$ & 134 & $30.5-40.7$ & 194 & 30.86 & 30.67 & 31.05 & 75.8 \\
\hline & M & $10.4-26.4$ & 88 & $24.2-33.8$ & 87 & 25.39 & 25.25 & 25.52 & 75.1 \\
\hline \multirow[t]{2}{*}{ E. pusillus } & $\mathrm{F}$ & $15.9-45.5$ & 201 & $41.9-50.2$ & 33 & 43.60 & 43.43 & 43.77 & 86.9 \\
\hline & M & $16.1-41.7$ & 207 & $35.4-47.9$ & 121 & 38.10 & 36.71 & 39.48 & 79.5 \\
\hline
\end{tabular}

deep-water longliners that target wreckfish, Polyprion americanus (Bloch \& Schneider, 1801) and European conger, Conger conger (Linnaeus, 1758). Scientific captures came from the INIAP-IPIMAR deep-water trawl cruise during the summer of 2003. Fishing took place at depths from $245 \mathrm{~m}$ to $745 \mathrm{~m}$, both on muddy (trawl) and rocky bottoms (longline).

Specimens were classified as mature or immature according to the maturity stages proposed by Stehmann (2002). For males, Stages 1 (immature) and 2 (maturing) were considered immature while Stages 3 (mature) and 4 (active) were considered mature. For females, Stages 1 (immature) and 2 (maturing) were considered immature while Stages 3 (mature), 4 (early pregnancy), 5 (middle pregnancy), 6 (late pregnancy) and 7 (resting) were considered mature. An immature specimen was considered a specimen that had never been mature and a mature specimen considered a specimen that was either mature or pregnant, or had been in the past.

Maturity ogives, to estimate the size at first maturity (total length at which $50 \%$ of the individuals are mature), were fitted by non-linear least-squares regression (PROC NLIN in the SAS (1988) system):

$\mathrm{P}_{\mathrm{i}}=\frac{1}{1+\mathrm{e}^{-\mathrm{b}\left(\mathrm{L}_{\mathrm{i}}-\mathrm{L}_{50}\right)}}$

where $\mathrm{P}_{\mathrm{i}}$ is the proportion of mature individuals in sizeclass $\mathrm{L}_{\mathrm{i}}$ of $1 \mathrm{~cm}, \mathrm{~b}$ is the slope and $\mathrm{L}_{50}$ is the size where $50 \%$ of the individuals are mature.

Maturity ogives were fitted to males and females separately and the Hotelling-T ${ }^{2}$ test (PROG IML in the SAS (1988) system) used to compare $\mathrm{L}_{50}$ sizes between sexes.

\section{RESULTS}

A total of 503 Etmopterus spinax $(65.2 \%$ females and $34.8 \%$ males) and 562 Etmopterus pusillus) (41.6\% females and $58.4 \%$ males) were collected for this study, and samples covered most of the length-ranges for both species. Specifically, lengths of E. spinax varied from 9.1 to $40.7 \mathrm{~cm}$ (10.4 to $33.8 \mathrm{~cm}$ in males and 9.1 to $40.7 \mathrm{~cm}$ in females) and in the case of E. pusillus from 15.9 to $50.2 \mathrm{~cm}$ (16.1 to $47.9 \mathrm{~cm}$ in males and 15.9 to $50.2 \mathrm{~cm}$ in females).

The estimated maturity ogives, with the respective equations, are presented in Figure 1. According to the Hotelling- $\mathrm{T}^{2}$ test, there were significant differences between sexes, with females maturing at significantly larger sizes than males, in both species.
Both species are late maturing. In E. spinax, size at first maturity was $30.86 \mathrm{~cm}$ for females $(75.8 \%$ of the maximum observed size) and $25.39 \mathrm{~cm}$ for males $(75.1 \%$ of the maximum observed size). In E. pusillus, size at first maturity was $43.60 \mathrm{~cm}$ for females $(86.9 \%$ of the maximum observed size) and $38.10 \mathrm{~cm}$ for males $(79.5 \%$ of the maximum observed size). In both species, females tended to grow and mature at larger sizes than males (Table 1).

\section{DISCUSSION}

Cortés (2000) examined 164 species of sharks and concluded that, on average, shark maturity begins at about $75 \%$ of their maximum size. In this study, Etmopterus spinax followed this general value, with both males and females maturing at around this value. This value had previously been observed for another species of lantern sharks, Etmopterus granulosus by Wetherbee (1996).

However, Etmopterus pusillus seemed to mature at a relatively larger size, especially in the case of females, where size at first maturity was estimated to be $87 \%$ of the maximum observed size. Given this fact, we can pose two hypotheses: (1) this value might be overestimated due to failure to capture the larger specimens, or (2) sample range was adequate and therefore females of this species mature very late in their life cycle. On one hand, and given the fact that most captured females were immature, we can consider that the larger specimens may occur mainly outside the sampled area, possibly in deeper water pupping grounds. On the other hand, Compagno (1984) described that maximum size for this species is at least $47 \mathrm{~cm}$, although it can grow larger. Since our largest specimen was $50.2 \mathrm{~cm}$, we may conclude that our sample probably covers most of this species length-range, in which case this species indeed matures at larger sizes than the usual $75 \%$ of maximum size.

In both species, size at first maturity was significantly higher for females than males. This fact seems to be common for sharks in general, and had previously been observed for a lantern shark, Etmopterus princeps, by Jakobsdottir (2001).

The late maturation of these deep-water sharks, especially in the case of Etmopterus pusillus, along with their characteristic slow growth rate and low fecundity, makes them very vulnerable to fishing mortality. Even though these lantern sharks are captured as by-catch and discarded immediately after capture, most specimens may 
die after capture, either due to the sudden pressure changes in the course of the fishing operation or due to handling while aboard the commercial fishing boats. Therefore, alternative by-catch reduction strategies such as the one proposed by Coelho et al. (2003) might be more adequate to prevent excessive fishing mortality on these species.

Since these specimens are never landed and not accounted for in fisheries statistics, there is no way to use fisheries data to assess population variations and trends through time.

This study was funded by FCT (Foundation for Science and Technology) through a PhD grant (Ref. SFRH/BD/10357/2002). The authors would like to thank Dr Ivone Figueiredo and Dr Pedro Bordalo Machado from INIAP-IPIMAR for providing part of the sample for this study. The authors are grateful to all fishermen who collaborated in collecting specimens for this study. Special thanks go to Ilídio Diogo and Francisco Diogo, skippers of the longliner 'Branca de Sagres', Helder Cavaco, skipper of the bottom trawler 'Gamba' and José Santos, skipper of the bottom trawler 'Crustáceo'.

\section{REFERENCES}

Carbonell, A., Alemany, F., Merella, P., Quetglas, A. \& Román, E., 2003. The by-catch of sharks in the western Mediterranean (Balearic Islands) trawl fishery. Fisheries Research, 61, 7-18.

Coelho, R., Bentes, L., Gonçalves, J.M.S., Lino, P.G., Ribeiro, J. \& Erzini, K., 2003. Reduction of elasmobranch by-catch in the hake semi-pelagic near bottom longline fishery in the Algarve (Southern Portugal). Fisheries Science, 69, 293-299.

Colloca, F., Cardinale, M., Belluscio, A. \& Ardizzone, G., 2003. Pattern of distribution and diversity of demersal assemblages in the central Mediterranean sea. Estuarine, Coastal and Shelf Science, 56, 469-480.

Compagno, L.J.V., 1984. Sharks of the world. An annotated and illustrated catalogue of shark species known to date. Part 1. Hexanchiformes to Lamniformes. FAO Fisheries Synopsis, no. 125, vol. 4, part 1, 249 pp.

Cortés, E., 2000. Life history patterns and correlations in sharks. Reviewes in Fisheries Science, 8, 299-344.

Erzini, K., Gonçalves, J.M.S., Bentes, L., Lino, P.G. \& Ribeiro, J., 2001. The hake deepwater semi-pelagic ('pedra-bola') longline fishery in the Algarve (southern Portugal). Fisheries Research, 51, 327-336.
Hareide, N. \& Garnes, G., 2001. The distribution and catch rates of deep water fish along the Mid-Atlantic Ridge from 43 to $61^{\circ}$ N. Fisheries Research, 51, 297-310.

Jakobsdottir, K.B., 2001. Biological aspects of two deep-water squalid sharks: Centroscyllium fabricii (Reinhardt, 1825) and Etmopterus princeps (Collett, 1904) in Icelandic waters. Fisheries Research, 51, 247-265.

Massutí, E. \& Moranta, J., 2003. Demersal assemblages and depth distribution of elasmobranchs from the continental shelf and slope off the Balearic Islands (western Mediterranean). ICES Journal of Marine Science, 60, 753-766.

Monteiro, P., Araújo, A., Erzini, K. \& Castro, M., 2001. Discards of the Algarve (southern Portugal) crustacean trawl fishery. Hydrobiologia, 449, 267-277.

Santos, J. \& Borges, T., 2001. Trophic relationships in deep-water fish communities off Algarve, Portugal. Fisheries Research, 51, 337-341.

SAS, 1988. SAS User's guide. North Carolina: SAS Institute.

Sion, L., D’Onghia, G. \& Carlucci, R., 2002. A simple technique for ageing the velvet belly shark, Etmopterus spinax (Squalidae). In Proceedings of the 4th Meeting of the European Elasmobranch Association, ICRAM, ARPAT \& SFI, Livorno, 28-30 September 2000 (ed. M. Vacchi et al.), pp. 135-139.

Smith, S.E., Au, D.W. \& Show, C., 1998. Intrinsic rebound potentials of 26 species of Pacific sharks. Marine and Freshwater Research, 49, 663-678.

Stehmann, M.F.W., 2002. Proposal of a maturity stages scale for oviparous and viviparous cartilaginous fishes (Pisces, Chondrichthyes). Archives of Fishery and Marine Research, 50, 2348.

Stevens, J.D., Bonfil, R., Dulvy, N.K. \& Walker, P.A., 2000. The effects of fishing on sharks, rays, and chimaeras (chondrichthyans), and the implications for marine ecosystems. ICES Fournal of Marine Science, 57, 476-494.

Wetherbee, B.M., 1996. Distribution and reproduction of the southern lantern shark from New Zealand. Fournal of Fish Biology, 49, 1186-1196. 